\title{
A Multicenter Phase II Study of Twice-Weekly Bortezomib plus Rituximab in Patients with Relapsed Follicular Lymphoma: Long-Term Follow-Up
}

\author{
Alessia Bari ${ }^{a} \quad$ Raffaella Marcheselli ${ }^{a} \quad$ Luigi Marcheselli $^{a} \quad$ Isabel Alvarez ${ }^{b}$ \\ Samantha Pozzi ${ }^{a}$ Paola Ferri ${ }^{a}$ Antonio Lazzaro ${ }^{c}$ Alberto Fragasso ${ }^{d}$ \\ Santo Neri ${ }^{\mathrm{e}}$ Luca Baldini ${ }^{f}$ Angelo Michele Carella ${ }^{g}$ Francesco Angrilli ${ }^{\text {h }}$ \\ Roberto Guarigliai Gabriele Buda ${ }^{j}$ Caterina Stelitanok ${ }^{k}$ Stefano Sacchi ${ }^{a}$ \\ on behalf of the Gruppo Italiano Studio Linfomi (GISL)
}

\begin{abstract}
a Program of Innovative Therapy in Oncology and Hematology, Department of Diagnostic, Clinical Medicine and Public Health, University of Modena and Reggio Emilia, Modena, ${ }^{\mathrm{b}} \mathrm{Hematology}$ Unit, Azienda Ospedaliera Arcispedale Santa Maria Nuova, IRCCS, Reggio Emilia, ' Hematology Unit, Guglielmo da Saliceto Hospital, Piacenza, ${ }^{d}$ Hematology Unit, Madonna delle Grazie Hospital, Matera, ${ }^{e}$ Hematology Unit, Papardo Hospital Messina, Messina, fDepartment of Hematology, Fondazione IRCCS Istituto Nazionale dei Tumori and University of Milan, Milan, ${ }^{g}$ Hematology Unit, San Martino Hospital, Genoa, h Department of Hematology, Ospedale Santo Spirito, Pescara, 'Hematology and SCT Unit, IRCCS-CROB, Centro di Riferimento Oncologico della Basilicata, Rionero in Vulture, jDivision of Hematology, Università Di Pisa, Pisa, and kHematology Unit, Bianchi Melacrino Morelli Hospital, Reggio Calabria, Italy
\end{abstract}

\section{Key Words}

Bortezomib - Chemotherapy-free regimen · Follicular lymphoma $\cdot$ Relapsed/progressive disease $\cdot$ Rituximab

\begin{abstract}
Single-agent bortezomib (B) has shown activity in heavily pretreated patients with relapsed/refractory indolent lymphoma. On the basis of these findings, we performed a phase Il study of B combined with rituximab (R) in patients with relapsed follicular lymphoma (FL). Forty-five patients with fairly good prognostic profiles were enrolled from 2007 to 2011 and received a total of 6 cycles of the $B+R$ combination. The end points were the overall response rate (ORR), progression-free survival (PFS), duration of remission (DoR), overall
\end{abstract}

survival (OS), and toxicity evaluation. When considering all the enrolled patients the ORR was $64 \%$. At 5 years, the estimated PFS, DoR, and OS were 34, 49, and 70\%, respectively. After excluding the 7 R-naïve patients, the ORR was 58\%, with a PFS of 19 months. The most common grade $>2$ toxicities were thrombocytopenia (18\%), peripheral neuropathy (13\%), and neutropenia (2\%). Our study shows the feasibility, long-term efficacy, and excellent tolerability of the $\mathrm{B}+\mathrm{R}$ combination. We are aware that our study has specific limitations, such as the small sample size consisting of patients with a relatively good prognostic profile. However, because FL patients will be treated with subsequent chemotherapy regimens, a well-tolerated and effective chemotherapy-free therapy could be considered an additional tool for long-term disease control.

\section{KARGER}

(c) 2016 S. Karger AG, Basel

E-Mail karger@karger.com

www.karger.com/aha
Stefano Sacchi, MD

Department of Diagnostic, Clinical Medicine and Public Health

University of Modena and Reggio Emilia, Via del Pozzo 71

IT-41123 Modena (Italy)

E-Mail stefano.sacchi@unimore.it 


\section{Introduction}

Follicular lymphoma (FL) is the second most frequently occurring subtype of malignant lymphoma in western countries and accounts for approximately $22 \%$ of all adult non-Hodgkin lymphoma [1]. A variety of treatment approaches including the use of alkylating agent monotherapies, combination therapy with or without doxorubicin, and combination chemoradiotherapy have been used to treat patients. In recent years, new therapeutic approaches have been investigated. These include myeloablative chemotherapy with stem cell rescue [2], purine analogues [3, 4], and immunologic therapy with naked, radiolabeled anti-CD20 monoclonal antibodies and inhibitors of B cell receptor signaling [5-8]. With the current treatment options, complete remission rates range from 65 to $85 \%$, the duration of the primary response is about 30 months, and the expected median survival is approximately $8-10$ years $[9,10]$. Although patients with FL have relatively long median survival times, they tend to relapse over time, with responses to salvage therapy of a shorter duration after every relapse, and they eventually die of their disease. Thus, innovative treatments are being explored to improve the response rate and survival outcome, and to avoid the side effects of classical chemotherapeutic regimens. FL cells express $\mathrm{CD} 20$, overexpress the anti-apoptotic protein $\mathrm{Bcl} 2$, and have a constitutively activated NF- $\kappa B$. This triple marker positivity provides the biological rationale for combining rituximab (R) and bortezomib (B). Indeed, $\mathrm{R}$ targets $\mathrm{CD} 20$ and $\mathrm{B}$ targets NF- $\mathrm{KB}$, and both strongly activate apoptosis. Furthermore, the combination demonstrated additive/synergistic activity in in vitro and in vivo murine models $[11,12]$, the toxicities are not overlapping, and a pharmacokinetic interaction is unlikely $[13,14]$. In phase I [15] and multiple phase II studies [16-19], B as a single agent showed activity in heavily pretreated patients with relapsed/refractory indolent lymphoma, utilized on either a biweekly or weekly schedule $[20,21]$. These findings encouraged several studies of different regimens combining $B$ with $R$ and chemotherapy in indolent lymphoma, the results of which have been published [22-24].

With this background, we performed a multicenter phase II study examining the safety and efficacy of $\mathrm{B}+\mathrm{R}$ in patients with relapsed FL. Here we present the results observed after a long-term follow-up period, which show excellent survival outcomes.

\section{Patients and Methods}

\section{Patients and Treatment}

Patients were enrolled in a multicenter, open-label, nonrandomized phase II study from 2007 to 2011, which was conducted at 10 Italian institutions (FOLREC03/LYM2024, ClinicalTrials. gov No. NCT01830465; EudraCT No. 2006-002521-23).

The inclusion criteria were for patients aged 18 years or older, with histologically proven FL (grade 1-3a) based on the World Health Organization classification [25], relapsed/progressive disease, and no more than 3 lines of treatment, a Karnofsky performance status $\geq 50 \%$, at least 1 measurable lesion, a life expectancy of more than 6 months, left ventricular ejection fraction $>50 \%$, and adequate renal and liver function. The exclusion criteria were CNS involvement, infection with human immunodeficiency virus, hepatitis $\mathrm{B}$ or $\mathrm{C}$ virus, another primary cancer, significant comorbidity (including preexisting neuropathy grade 2 or higher), severe impairment of bone marrow function (absolute neutrophils count $<1.5 \times 10^{9} / 1$ or platelets $<50 \times 10^{9} / 1$ unless due to lymphoma involvement), and pregnancy, breast feeding, or refusing to use an acceptable method of contraception for the duration of the study.

All patients provided written informed consent. The institutional review board at all of the participating institutions approved the study, which was conducted according to the provisions of the Declaration of Helsinki, International Conference on Harmonization, and Guidelines for Good Clinical Practice.

Patients with relapsed/progressive FL received a total of $6 \mathrm{cy}$ cles of B and 6 infusions of R. B (VELCADE ${ }^{\circledR}$; Johnson \& Johnson/ Janssen-Cilag S.p.A) was delivered as an intravenous bolus at a dose of $1.3 \mathrm{mg} / \mathrm{m}^{2}$ on days $1,4,8$, and 11 for six 21-day courses (cycles I-VI). R was administered as an intravenous infusion at the dose of $375 \mathrm{mg} / \mathrm{m}^{2}$ on day 1 of cycles III, IV, V, and VI. Two additional doses were administered in weeks 3 and 6 after cycle VI. Dose modification was permitted in cases of neutropenia, thrombocytopenia, and neurotoxicity. Prophylactic antiviral agents, filgrastim, and antibiotics were permitted according to the treating physician's discretion.

\section{Pretreatment and Safety and Efficacy Assessments}

Hematological parameters, clinical chemistry, and performance status were assessed on day 1 of each cycle, at the end of treatment, and at each follow-up visit, which occurred every 3 months for the first year then every 6 months until relapse or progression. Pretreatment and efficacy assessments included a physical examination, laboratory parameters, CT scans of the chest, abdomen and pelvis, and bone marrow biopsy. During follow-up, CT scans were scheduled every 6 months until relapse or progression. Responses were evaluated at the end of cycle II, and 1 month after the end of treatment.

\section{Outcomes}

The primary endpoint was the overall response rate (ORR) at the end of treatment ( 6 cycles of $B$ and 6 infusions of R) defined as the number of patients who achieved complete (CR) and partial $(\mathrm{PR})$ responses. The responses were evaluated in accordance with the International Working Group Criteria for Non-Hodgkin Lymphomas [26].

The secondary endpoints were ORR after 2 cycles of treatment (only B injections) and progression-free survival (PFS), defined as 
Table 1. Baseline characteristics $(n=45)$

\begin{tabular}{|c|c|c|c|}
\hline Variable & $\mathrm{n}$ & $\%$ & Median (range) \\
\hline Age, years & 45 & & $65(36-82)$ \\
\hline $\mathrm{Hb}, \mathrm{g} / \mathrm{dl}$ & 43 & & $13.3(10.2-16.0)$ \\
\hline WBC, $\times 10^{9} / 1$ & 43 & & $5.7(2.3-62)$ \\
\hline Lymphocytes, $\times 10^{9} / 1$ & 42 & & $1.34(0.14-6.27)$ \\
\hline Age $>60$ years & 29 & 64 & \\
\hline Male & 23 & 51 & \\
\hline \multicolumn{4}{|l|}{ AA stage } \\
\hline I & 5 & 11 & \\
\hline II & 7 & 16 & \\
\hline III & 14 & 31 & \\
\hline IV & 19 & 42 & \\
\hline With B-symptoms & 3 & 7 & \\
\hline \multicolumn{4}{|l|}{$\mathrm{LDH}(\mathrm{n}=41)$} \\
\hline$\leq \mathrm{ULN}$ & 29 & 71 & \\
\hline$>\mathrm{ULN}$ & 12 & 29 & \\
\hline \multicolumn{4}{|l|}{ Nodal sites } \\
\hline $0-4$ & 32 & 71 & \\
\hline$>4$ & 13 & 29 & \\
\hline \multicolumn{4}{|l|}{ Extranodal sites } \\
\hline$>1$ & 5 & 11 & \\
\hline Bulky disease $^{1}$ & 3 & 7 & \\
\hline $\mathrm{BM}$ involvement & 9 & 20 & \\
\hline \multicolumn{4}{|l|}{ FLIPI $(n=41)$} \\
\hline $0-1$ & 17 & 41 & \\
\hline 2 & 8 & 20 & \\
\hline $3-5$ & 16 & 39 & \\
\hline \multicolumn{4}{|l|}{ Histology } \\
\hline Grade 1 & 21 & 47 & \\
\hline Grade 2 & 12 & 27 & \\
\hline Grade 3a & 11 & 24 & \\
\hline $\mathrm{NA}^{2}$ & 1 & 2 & \\
\hline \multicolumn{4}{|l|}{ Prior lines ${ }^{3}$} \\
\hline 1 & 18 & 40 & \\
\hline 2 & 17 & 38 & \\
\hline 3 & 10 & 22 & \\
\hline \multicolumn{4}{|c|}{ Time from the last treatment } \\
\hline$<1$ year & 10 & 22 & \\
\hline $1-3$ years & 17 & 38 & \\
\hline $3-5$ years & 10 & 22 & \\
\hline$>5$ years & 8 & 18 & \\
\hline
\end{tabular}

$\mathrm{AA}=$ Ann Arbor; $\mathrm{LDH}=$ lactate dehydrogenase; $\mathrm{UNL}=$ upper limit of normality; $\mathrm{BM}=$ bone marrow.

${ }^{1}$ One mediastinal site with a diameter of $8 \mathrm{~cm}$ and 2 nonmediastinal sites with diameters of 8 and $12 \mathrm{~cm}$.

${ }^{2}$ Patient with a diagnosis of FL not otherwise specified.

${ }^{3}$ Number of lines of antineoplastic treatment.

the time from study entry to the time of any documented progressive disease, relapse, or death from any cause. Duration of remission (DoR) was defined as the time from CR/PR confirmation to the time of any documented relapse/progressive disease or death from any cause. Overall survival (OS) was defined as the time from study entry to the last observation or death from any cause.

Bortezomib plus Rituximab in Relapsed FL
Table 2. Patient disposition and treatment exposure (safety population; $\mathrm{n}=45$ )

\begin{tabular}{lr}
\hline Median cycles, $\mathrm{n}$ & $6(1-8)$ \\
Patients completing all 8 cycles, $\mathrm{n}$ & $21(47)$ \\
Patients completing at least 6 cycles, $\mathrm{n}$ & $29(64)$ \\
Reason for discontinuing before completing & \\
8 cycles, $\mathrm{n}$ & \\
SD/PD & $12(27)$ \\
PN & $7(16)$ \\
$\quad$ AEs & $2(4)$ \\
Investigator decision/patient choice & $3(7)$ \\
Median R dose intensity, \% & 94 \\
Median B dose intensity, \% & 97
\end{tabular}

Values in parentheses are the percentage or range. $\mathrm{SD}=$ Stable disease $\mathrm{PD}=$ progressive disease; $\mathrm{AEs}=$ adverse events.

Safety was evaluated by assessing the laboratory parameters and adverse events. Adverse events were graded using the National Cancer Institute Common Terminology Criteria for Adverse Events (CTCAE version 3.0).

\section{Study Design and Statistical Analysis}

The study was planned according to Simon's optimal two-stage design [27], with ORR as the primary endpoint. With a significance level of $\alpha=0.05$ and power of $90 \%$, we considered ORR rates of $40 \%$ as a level of no interest (P0) and $60 \%$ as a level of interest (P1). In the first stage 17 evaluable patients were enrolled and, if more than 8 responses were observed, 24 additional patients were enrolled in the second stage. The study regimen was considered ineffective with less than 22 overall responses observed at the final assessment. Given that approximately $10 \%$ of patients were expected to be deemed ineligible after registration for any reason, we planned to recruit a total of 45 patients. Sample size was determined with a one-sided test. The baseline characteristics of the patients were summarized as numbers and percentages for categorical variables and as medians and ranges for continuous variables.

The response rates were reported with the exact binomial 95\% confidence intervals (CIs). Kaplan-Meier methodology was used to estimate OS, PFS, and DoR [28]. Safety was analyzed taking into consideration all patients who received at least 1 dose of a study drug. All analyses were done with Stata SE/10 package.

\section{Results}

\section{Patient Characteristics}

Between 2007 and 2011, 45 patients with relapsed FL were enrolled in the FOLREC03/LYM2024 clinical trial. The baseline clinical characteristics and prior therapies are detailed in table 1 . The median age at study entry was 65 years (range $36-82$ ), 51\% were males, and 39\% had a 
Fig. 1. Study flow chart and reasons for discontinuation. $\mathrm{PD}=$ Progressive disease; $\mathrm{SD}=$ stable disease; $\mathrm{CR}=$ complete response; $\mathrm{PR}=$ partial response.

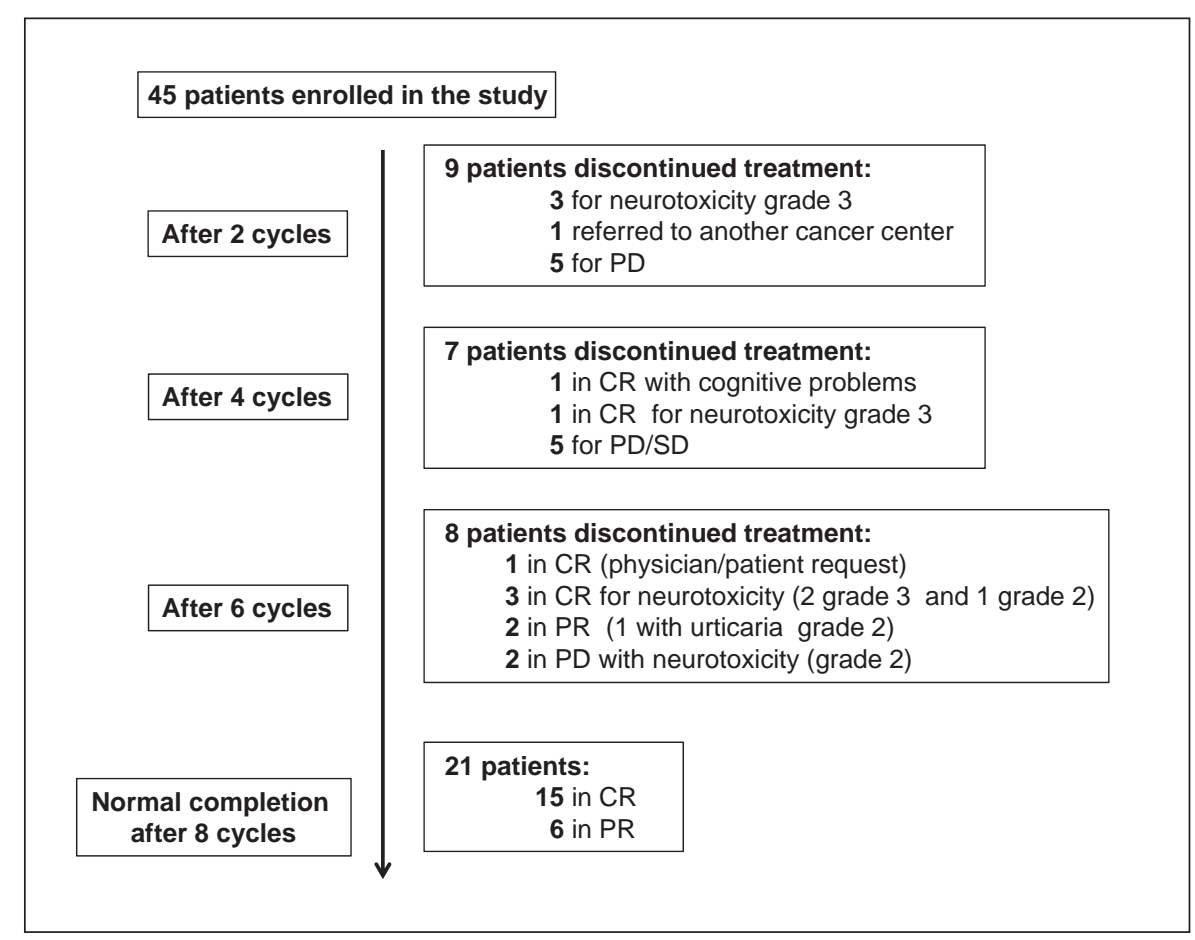

Table 3. Response after treatment with $B+R$ and after the first 2 cycles of therapy (B injection only) in the 45 eligible patients

\begin{tabular}{lrrr}
\hline \multicolumn{1}{c}{$\mathrm{n}$} & $\%$ & $95 \% \mathrm{CI}^{1}$ \\
\hline Response & & & \\
ORR & 29 & 64 & $49-78$ \\
$\quad$ CR & 21 & 47 & $32-62$ \\
$\quad$ PR & 8 & 18 & $8-32$ \\
SD & 1 & 2 & $0-12$ \\
PD & 11 & 24 & $13-40$ \\
EF/W & 4 & 9 & $2-21$ \\
\hline Response after 2 cycles of therapy & & & \\
ORR & 15 & 34 & $20-49$ \\
$\quad$ CR & 3 & 7 & $1-18$ \\
$\quad$ PR & 12 & 27 & $15-42$ \\
SD & 21 & 47 & $32-62$ \\
PD & 5 & 11 & $4-24$ \\
EF/W & 4 & 9 & $2-21$ \\
\hline
\end{tabular}

$\mathrm{PD}=$ Progressive disease $\mathrm{SD}=$ stable disease $\mathrm{EF} / \mathrm{W}=$ early failure/withdrawal after the first 2 cycles of treatment ( 3 for neurotoxicity and 1 referred to another cancer center); ORR = overall response rate; $\mathrm{CR}=$ complete response; $\mathrm{PR}=$ partial response.

${ }^{1}$ Based on binomial distribution.
Follicular Lymphoma International Prognostic Index (FLIPI) [29] score of 3-5. Before registering in the study, $18(40 \%), 17$ (38\%), and 10 (22\%) patients had been treated with 1,2 , and 3 prior lines of therapy, respectively. Seven (16\%) of these patients were $\mathrm{R}$ naïve but had previously been treated with chemotherapy.

\section{Treatment Exposure}

Patients received a median of 6 cycles of $\mathrm{B}+\mathrm{R}$ (range $1-8)$. In total, 20,16 , and $18 \%$ received 2,4 , and 6 cycles, respectively, and $47 \%$ completed the assigned treatment. The median dose intensity delivered was 0.972 and 0.939 for B and R, respectively (table 2). After 2 courses, 9 patients (20\%) withdrew from the trial (fig. 1). After 4 courses, another 7 patients (16\%) withdrew, and 8 patients (18\%) withdrew after 6 cycles. Twenty-one patients (47\%) received all 6 cycles of therapy plus the 2 additional doses of R.

\section{Efficacy}

The efficacy criteria for the first-stage analysis were met ( 11 of the first 17 patients achieved CR/PR), and the enrollment continued to the planned final accrual of 45 patients. The treatment responses are summarized in table 3. Twenty-nine patients achieved CR/PR for an ORR 


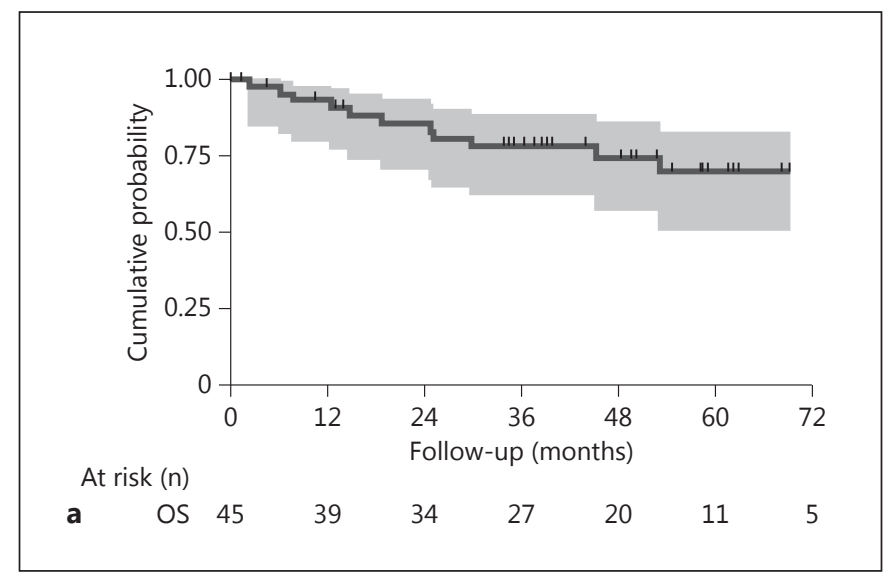

Fig. 2. Kaplan-Meier estimates of OS (a) and PFS (b) of the 45 patients. c DoR of the 29 patients who obtained CR or PR at the end of therapy.

of $64 \%$ (95\% CI 49-78); of these patients, 21 (47\%, 95\% CI 49-71) and 8 (18\%, 95\% CI 8-32) achieved CRs and PRs, respectively. One patient $(2 \%, 95 \%$ CI $0-12)$ had stable disease and 11 (24\%, 95\% CI 13-40) progressed. Four patients (9\%, 95\% CI 2-21) withdrew from the study before the first 2 cycles of therapy. The ORR after 2 cycles of therapy (i.e. after receiving only B) was $34 \%$ (95\% CI 20-49) with 3 (7\%) achieving CR and 12 (27\%) achieving PR. After a median follow-up of 52 months (range 1-91), we observed 11 (24\%) deaths: 8 from progressive disease, 1 from heart failure, 1 from sudden death, and 1 from an unknown cause. The median PFS was 22 months (95\% CI 13-54) and the median DoR was 50 months (95\% CI 14 to not reached). The median OS was not reached. At 5 years, the estimated PFS, DoR, and OS were $34 \%$ (95\% CI 20-49\%), 49\% (95\% CI 28-67\%), and 70\% (95\% CI 51-82\%), respectively (fig. 2). A separate analysis excluding the $7 \mathrm{R}$-naïve patients showed an ORR of 58\% (37\% CR and 21\% PR) with a PFS of 19 months (95\% CI 10-20).

Bortezomib plus Rituximab in Relapsed FL
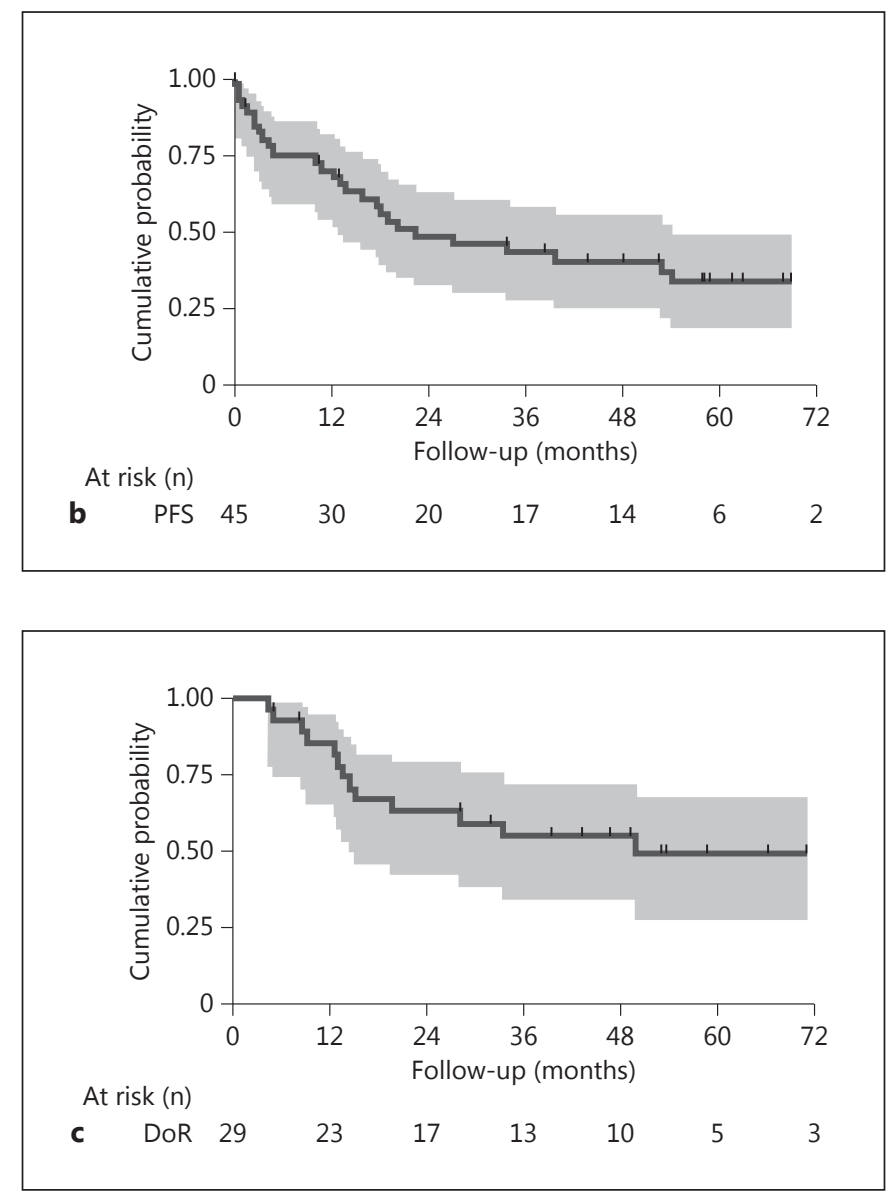

\section{Toxicity}

Toxicity was evaluable in all 45 patients. The $\mathrm{B}+\mathrm{R}$ combination was generally well tolerated considering that the study population was relapsed patients, and no deaths due to toxicity were observed. As detailed in table 4 , most toxicities were grade 1 and 2 , with a low frequency of grade 3 and 4 adverse events. The most common serious adverse events of grade $>2$ were thrombocytopenia (18\%), peripheral neuropathy $(\mathrm{PN})(13 \%)$, and neutropenia (2\%). No cases of grade $>2$ anemia were reported. Overall, 6 (13\%) patients experienced grade 3 $\mathrm{PN}$. However, the treating physicians decided to stop the therapy due to $\mathrm{PN}$ in 7 patients, despite it being grade 2 in 3 of these patients. Grade $\geq 2$ thrombocytopenia was more frequent between cycles I and IV, whereas grade $\geq 2$ neurotoxicity was more frequent after 5 cycles of treatment. 
Table 4. Side effects of $B+R$ treatment (evaluable in all 45 patients)

\begin{tabular}{|c|c|c|c|c|c|c|c|c|c|c|}
\hline & \multicolumn{2}{|c|}{ Anemia } & \multicolumn{2}{|c|}{$\begin{array}{l}\text { Neutro- } \\
\text { penia }\end{array}$} & \multicolumn{2}{|c|}{$\begin{array}{l}\text { Thrombocy- } \\
\text { topenia }\end{array}$} & \multicolumn{2}{|c|}{ Infections } & \multicolumn{2}{|l|}{ PN } \\
\hline & $\mathrm{n}$ & $\%$ & $\mathrm{n}$ & $\%$ & $\mathrm{n}$ & $\%$ & $\mathrm{n}$ & $\%$ & $\mathrm{n}$ & $\%$ \\
\hline \multicolumn{11}{|l|}{ Grade } \\
\hline 0 & 25 & 56 & 34 & 76 & 24 & 53 & 34 & 76 & 22 & 49 \\
\hline 1 & 16 & 36 & 5 & 11 & 12 & 27 & & & 4 & 9 \\
\hline 2 & 4 & 9 & 5 & 11 & 1 & 2 & 10 & 22 & 13 & 29 \\
\hline 3 & & & 1 & 2 & 7 & 16 & 1 & 2 & 6 & 13 \\
\hline 4 & & & & & 1 & 2 & & & & \\
\hline Total & 45 & & 45 & & 45 & & 45 & & 45 & \\
\hline
\end{tabular}

Grades are according to the NCI Common Toxicity Criteria classification.

\section{Discussion}

Despite great progress in the treatment of FL in recent years, there is still no cure. Although patient survival is longer, the evolution of the disease has not changed and is still characterized by a succession of ever more frequent recurrences. Eventually, patients die from progressive disease or complications that are usually treatment related. The ability to use treatments other than standard chemotherapy that are still highly effective, such as the combination of $\mathrm{B}+\mathrm{R}$, is therefore extremely important.

The finding from this multicenter, open-label, nonrandomized phase II study confirmed that the combination of $\mathrm{R}$ with a twice-weekly injection of $\mathrm{B}$ was effective in relapsed FL patients. Considering all of the enrolled patients, the ORR was $64 \%$ and the CR rate was $47 \%$. After a long-term follow-up of 52 months, we observed a median PFS of 22 months and an excellent median DoR of 50 months, while the median OS was not yet reached. At 5 years, estimated PFS, DoR, and OS were 34,49 , and $70 \%$, respectively. The considerable length of the DoR highlights the good efficacy of the combination. After excluding the 7 R-naïve patients, we still observed a good ORR of $58 \%$ (37\% CR, 21\% PR), with a PFS of 19 months.

A recent randomized trial [22] comparing $B+R$ to $R$ alone showed a median PFS of 12.8 months (range 11.515.0) after a median follow-up of 33.9 months in the $\mathrm{B}+\mathrm{R}$ group $(\mathrm{n}=340)$, with an ORR of $63 \%$, including $25 \%$ CRs. Comparing our results with those obtained in the $\mathrm{B}+\mathrm{R}$ arm of the randomized study, we observed that the CR rate was much higher ( 47 vs. $25 \%$ ) and the PFS longer (22 vs. 12.8 months) in our study. We also observed better outcomes in terms of CR and PFS when comparing the results of the subanalysis that excluded the $7 \mathrm{R}$-naïve patients with the results of the $\mathrm{B}+\mathrm{R}$ arm of the randomized study: CR was 37 versus $25 \%$, and PFS was 19 versus 12.8 months. The low risk profile of our study population could partially explain these good results.

In terms of toxicity, we confirmed that $\mathrm{B}+\mathrm{R}$ was generally well tolerated with manageable toxicities, considering that the patients were relapsed or had progressive disease, with a low rate of grade $\geq 3$ adverse events. The most common serious adverse events were thrombocytopenia, neurotoxicity, and neutropenia. The favorable tolerability was evidenced by the fact that $64 \%$ of the patients completed at least 6 cycles of therapy, and the median $\mathrm{B}+\mathrm{R}$ dose intensity was 0.972 and 0.939 , respectively. Furthermore, we did not observe late toxicities over the longterm follow-up such as second neoplasms. The $42 \%$ of patients who experienced grade $2 / 3 \mathrm{PN}$ tended to improve over time, and $26 \%$ recovered fully.

We are aware that our study has specific limitations. First, the small sample size weakened the strength of the statistical analysis, particularly that of efficacy. Second, and for the same reason, the $95 \%$ CIs around the survival outcomes were large. Third, our study population had a relatively good prognostic profile. Indeed, only $39 \%$ of the patients were classified as FLIPI 3-5, 40\% received only 1 prior line of therapy, $16 \%$ were $\mathrm{R}$ naïve, $20 \%$ had bone marrow involvement, $7 \%$ had bulky disease, and $29 \%$ had $>4$ nodal site involvements. The low risk profile of several patients enrolled in the trial may partially explain the better results we observed in comparison with the $\mathrm{B}+\mathrm{R}$ arm of the randomized trial [22]. The strengths of our study include the very long follow-up (more than 5 years) and the precise and careful evaluation of side effects.

In conclusion, after a very long follow-up period our study shows the feasibility, considerable efficacy, and excellent tolerability of the $\mathrm{B}+\mathrm{R}$ combination in patients with advanced-stage FL. Taking into account that FL is an incurable disease and that patients will be treated with subsequent chemotherapy regimens, the availability of an effective chemotherapy-free regimen with a relatively low toxicity provides an additional tool for the long-term control of FL.

Finally, even after considering the limitations of the study, we believe that our results provide enough clinical information for the use of the $\mathrm{B}+\mathrm{R}$ combination in clinical practice and that our findings are important for the general onco-hematologist.
Bari et al. 


\section{Acknowledgments}

The authors thank the patients for their participation in this study. The study was supported in part by the Associazione Angela Serra per la Ricerca sul Cancro, Modena, Italy, and by research funding from Johnson \& Johnson/Janssen-Cilag S.p.A.

\section{Author Contributions}

S.S.: conception and design of the study, interpretation of the data, final approval of the version to be published. L.M., R.M., and P.F.: statistical analysis, data collection, interpretation of data, and creation of tables and figures. S.S., R.M., A.B., and S.P. wrote the manuscript. S.S., I.A., S.P., A.L., A.F., S.N., L.B., A.M.C., F.A., R.G., G.B., C.S., and A.B. participated in the patients' care, data recording, and the interpretation of the data. All authors contributed critically to the drafting of the article and approved the final version.

\section{Disclosure Statement}

All authors report no potential conflicts of interest.

\section{References}

1 Aurora V, Winter JN: Current controversies in follicular lymphoma. Blood Rev 2006;20: 179-200.

2 Corradini P, Astolfi M, Cherasco C, Ladetto M, Voena C, Caracciolo D, Pileri A, Tarella C: Molecular monitoring of minimal residual disease in follicular and mantle cell nonHodgkin's lymphomas treated with highdose chemotherapy and peripheral blood progenitor cell autografting. Blood 1997;89: 724-731.

3 Redman JR, Cabanillas F, Velasquez WS, McLaughlin P, Hagemeister FB, Swan F Jr, Rodriguez MA, Plunkett WK, Keating MJ: Phase II trial of fludarabine phosphate in lymphoma: an effective new agent in low-grade lymphoma. J Clin Oncol 1992;10:790-794.

4 Sacchi S, Pozzi S, Marcheselli R, Federico M, Tucci A, Merli F, Orsucci L, Liberati M, Vallisa D, Brugiatelli M; Italian Lymphoma Study Group: Rituximab in combination with fludarabine and cyclophosphamide in the treatment of patients with recurrent follicular lymphoma. Cancer 2007;1:121-128.

5 McLaughlin P, Grillo-López AJ, Link BK, Levy R, Czuczman MS, Williams ME, Heyman MR, Bence-Bruckler I, White CA, Cabanillas F, Jain V, Ho AD, Lister J, Wey K, Shen D, Dallaire BK: Anti-CD20 monoclonal antibody therapy for relapsed indolent lymphoma: half of patients respond to a four-dose treatment program. J Clin Oncol 1998;16: 2825-2833.

6 Hohloch K, Delaloye AB, Windemuth-Kieselbach C, Gómez-Codina J, Linkesch W, Jurczak W, Cacchione R, Suh C, Zinzani PL, Trümper L: Radioimmunotherapy confers long-term survival to lymphoma patients with acceptable toxicity: registry analysis by the International Radioimmunotherapy Network. J Nucl Med 2011;52:1354-1360.

7 Kaminski MS, Zasadny KR, Francis IR, Fenner MC, Ross CW, Milik AW, Estes J, Tuck M, Regan D, Fisher S, Glenn SD, Wahl RL: Iodine-131-anti-B1 radioimmunotherapy for B-cell lymphoma. J Clin Oncol 1996;14: 1974-1981.
8 Blum KA: B-cell receptor pathway modulators in NHL. Hematol Am Soc Hematol Educ Program 2015;2015:82-91.

9 Liu Q, Fayad L, Cabanillas F, Hagemeister FB, Ayers GD, Hess M, Romaguera J, Rodriguez MA, Tsimberidou AM, Verstovsek S, Younes A, Pro B, Lee MS, Ayala A, McLaughlin P: Improvement of overall and failure-free survival in stage IV follicular lymphoma: 25 years of treatment experience at The University of Texas M.D. Anderson Cancer Center. J Clin Oncol 2006;24:1582-1589.

10 Sacchi S, Pozzi S, Marcheselli L, Bari A, Luminari S, Angrilli F, Merli F, Vallisa D, Baldini L, Brugiatelli M; Italian Lymphoma Study Group: Introduction of rituximab in frontline and salvage therapies has improved outcome of advanced-stage follicular lymphoma patients. Cancer 2007;109:2077-2082.

11 Hernandez-llizzaliturri FJ, Kotowski A, Czuzman MS: PS341 inhibits cell proliferation, induces apoptosis of and ananches the biological effects of rituximab on non-Hodgkins lymphoma (NHL) cell lines and lymphoma xenografts. 45th Annual Meeting of the America Society of Hematology, San Diego, December 6-9, 2003. Blood Conf 2003;102: 903.

12 Smolewski P, Duechler M, Linke A, Cebula B, Grzybowska-Izydorczyk O, Shehata M, Robak T: Additive cytotoxic effect of bortezomib in combination with anti-CD20 or anti-CD52 monoclonal antibodies on chronic lymphocytic leukemia cells. Leuk Res 2006;30:15211529.

13 Reece DE, Sullivan D, Lonial S, Mohrbacher AF, Chatta G, Shustik C, Burris H 3rd, Venkatakrishnan K, Neuwirth R, Riordan WJ, Karol M, von Moltke LL, Acharya M, Zannikos P, Keith Stewart A: Pharmacokinetic and pharmacodynamic study of two doses of bortezomib in patients with relapsed multiple myeloma. Cancer Chemoter Pharmacol 2011; 67:57-67.
14 Cartron G, Blasco H, Paintaud G, Watier H, Le Guellec C: Pharmacokinetics of rituximsb and its clinical use: thought for the best use? Crit Rev Oncol Hematol 2007;62:43-52.

15 Orlowski RZ, Stinchcombe TE, Mitchell BS, Shea TC, Baldwin AS, Stahl S, Adams J, Esseltine DL, Elliott PJ, Pien CS, Guerciolini R, Anderson JK, Depcik-Smith ND, Bhagat R, Lehman MJ, Novick SC, O'Connor OA, Soignet SL: Phase I trial of the proteasome inhibitor PS-341 in patients with refractory hematological malignancies. J Clin Oncol 2002;20: 4420-4427.

16 Goy A, Younes A, McLaughlin P, Pro B, Romaguera JE, Hagemeister F, Fayad L,Dang $\mathrm{NH}$, Samaniego F, Wang M, Broglio K, Samuels B, Gilles F, Sarris AH, Hart S, Trehu E, Schenkein D, Cabanillas F, Rodriguez AM: Phase II study of proteasome inhibitor bortezomib in relapsed or refractory B-cell nonHodgkin's lymphoma. J Clin Oncol 2005;23: 667-675.

17 O’Connor OA, Wright J, Moskowitz C, Muzzy J, MacGregor-Cortelli B, Stubblefield M, Straus D, Portlock C, Hamlin P, Choi E, Dumetrescu O, Esseltine D, Trehu E, Adams J, Schenkein D, Zelenetz AD: Phase II clinical experience with the novel proteasome inhibitor bortezomib in patients with indolent nonHodgkin's lymphoma and mantle cell lymphoma. J Clin Oncol 2005;23:676-684.

18 Strauss SJ, Maharaj L, Hoare S, Johnson PW, Radford JA, Vinnecombe S, Millard L, Rohatiner A, Boral A, Trehu E, Schenkein D, Balkwill F, Joel SP, Lister TA: Bortezomib therapy in patients with relapsed or refractory lymphoma: potential correlation of in vitro sensitivity and tumor necrosis factor alpha response with clinical activity. J Clin Oncol 2006;24:2105-2112.

19 Di Bella N, Taetle R, Kolibaba K, Boyd T, Raju R, Barrera D, Cochran EW Jr, Dien PY, Lyons R, Schlegel PJ, Vukelja SJ, Boston J, Boehm KA, Wang Y, Asmar L: Results of a phase 2 study of bortezomib in patients with relapsed or refractory indolent lymphoma. Blood 2010;115:475-480. 
20 Gerecitano J, Portlock C, Moskowitz C, Hamlin P, Straus D, Zelenetz AD, Zhang Z, Dumitrescu O, Sarasohn D, Lin D, Pappanicholaou J, Cortelli BM, Neylon E, Hamelers R, Wright J, O'Connor OA: Phase 2 study of weekly bortezomib in mantle cell and follicular lymphoma. Br J Haematol 2009; 146:652-655.

21 Ribrag V, Tilly H, Casasnovas O, Bosly A, Bouabdallah R, Delarue R, Boue F, Bron D, Feugier P, Haioun C, Offner F, Coiffier B: Efficacy and toxicity of two schedules of bortezomib in patients with recurrent or refractory follicular lymphoma: a randomised phase II trial from the Groupe d'Etude des Lymphomes dell'Adulte (GELA). Eur J Cancer 2013;49:904-910.

22 Coiffier B, Osmanov EA, Hong X, Scheliga A, Mayer J, Offner F, Rule S, Teixeira A, Walewski J, de Vos S, Crump M, Shpilberg O, Esseltine DL, Zhu E, Enny C, Theocharous P, van de Velde H, Elsayed YA, Zinzani PL; LYM3001 Study Investigators: Bortezomib plus rituximab versus rituximab alone in patients with relapsed, rituximab-naive or rituximabsensitive, follicular lymphoma: a randomised phase 3 trial. Lancet Oncol 2011;12:773-784.
23 Zinzani PL, Khuageva NK, Wang H, Garicochea B, Walewski J, Van Hoof A, Soubeyran P, Caballero D, Buckstein R, Esseltine DL, Theocharous P, Enny C, Zhu E, Elsayed YA, Coiffier B: Bortezomib plus rituximab versus rituximab in patients with high-risk, relapsed, rituximab-naïve or rituximab-sensitive follicular lymphoma: subgroup analysis of a randomized phase 3 trial. J Hematol Oncol 2012; 5:67.

24 Evens AM, Smith MR, Lossos IS, Helenowski I, Millenson M, Winter JN, Rosen ST, Gordon LI: Frontline bortezomib and rituximab for the treatment of newly diagnosed high tumour burden indolent non-Hodgkin lymphoma: a multicentre phase II study. Br J Haematol 2014;166:514-520.

25 World Health Organization: Classification of Tumors of Haematopoietic and Lymphoid Tissues. Lyon, IARC Press, 2008.
26 Cheson BD, Horning SJ, Coiffier B, Shipp MA, Fisher RI, Connors JM, Lister TA, Vose J, Grillo-López A, Hagenbeek A, Cabanillas F, Klippensten D, Hiddemann W, Castellino R, Harris NL, Armitage JO, Carter W, Hoppe R, Canellos GP: Report of an international workshop to standardize response criteria for non-Hodgkin's lymphoma. J Clin Oncol 1999;17:1244-1253.

27 Simon R: Optimal two-stage designs for phase II clinical trials. Control Clin Trials 1989;10: 1-10.

28 Kaplan EL, Meier P: Nonparametric estimation from incomplete observations. J Am Stat Assoc 1958;53:457-481.

29 Solal-Céligny P, Roy P, Colombat P, White J, Armitage JO, Arranz-Saez R, Au WY, Bellei M, Brice P, Caballero D, Coiffier B, CondeGarcia E, Doyen C, Federico M, Fisher RI, Garcia-Conde JF, Guglielmi C, Hagenbeek A, Haïoun C, Le Blanc M, Lister AT, LopezGuillermo A, McLaughlin P, Milpied N, Morel P, Mounier N, Proctor SI, Rohatiner A, Smith P, Soubeyran P, Tilly H, Vitolo U, Zinzani PL, Zucca E, Montserrat E: Follicular lymphoma international prognostic index. Blood 2004;104:1258-1265. 